12 - ARTIGO ORIGINAL

\title{
Proteção pela glucana em modelo experimental de sepse ${ }^{1}$
}

\author{
Protection for glucan in experimental model of sepsis
}

\section{Janaina Cristiana de Oliveira Crispim Freitas ${ }^{2}$, Aldo da Cunha Medeiros ${ }^{3}$, Valéria Soraya de Farias Sales ${ }^{4}$}

1. Trabalho de Dissertação do Mestrado Desenvolvido no Programa de Pós Graduação em Ciências Farmacêuticas - UFRN, em colaboração com o Núcleo de Cirurgia Experimental.

2. Aluna do Mestrado no Programa de Pós Graduação em Ciências Farmacêuticas-UFRN.

3. Doutor em Cirurgia, chefe do Núcleo de Cirurgia Experimental, Prof. Adjunto e Coordenador da Disciplina de Técnica Operatória-UFRN, Pesquisador nível I do CNPq.

4. Professora Doutora da Disciplina de Imunologia Clínica-UFRN.

\section{RESUMO}

OBJETIVO: Neste trabalho avaliou-se a ação da glucana ?? 1-3 insolúvel, um polissacarídeo extraído da parede celular interna do fungo Saccharomyces cerevisae, como agente imunoestimulante inespecífico em camundongos submetidos a modelo de sepse experimental.

MÉTODOS: Foram utilizados 73 camundongos Swiss, os quais receberam glucana em diferentes doses pelas vias intraperitoneal (i.p.). Sepse difusa foi induzida através da técnica de ligadura e punção do ceco, transfixado e drenado com fio multifilamentar.

RESULTADOS: Os animais tratados com glucana apresentaram um aumento significante no número de leucócitos no lavado peritoneal, diminuição no número de unidades formadoras de colônias bacterianas. Observou-se um aumento significante na sobrevida dos animais tratados com glucana insolúvel, a qual proporcionou um maior controle da infecção bacteriana por aumentar o número de células de defesa.

CONCLUSÃO: A glucana insolúvel, quando usada em camundongos por via intraperitoneal, em modelo de sepse abdominal, contribuiu para melhorar a sobrevida, induziu proteção contra a formação de colônias bacterianas no líquido peritoneal e aumentou a migração leucocitária.

Descritores: Glucana insolúvel. Sepse. Sobrevida. Colônias bacterianas. Migração leucocitária.

\footnotetext{
ABSTRACT

PURPOSE: This study evaluated the insoluble (1 ? 3) B-glucan action, a polysaccharide isolated from the inner cell wall of the yeast Saccharomyces cerevisiae, as nonspecific immunostimulant agent in mice underwent experimental model of sepsis.
} 
METHODS: Seventy three Swiss mices received different doses of glucan by intraperitoneal (i.p.) administrations. Difuse sepsis was induced by the cecal puncture and ligation.

RESULTS: The glucan-treated group showed a significant increase in the leukocyte number at the peritoneal fluid, and decrease in the bacterial colony-forming units. It was observed an increase in the survival rate at the insoluble glucan-treated group, when compared to controls.

CONCLUSION: The insoluble glucan, when used in mices with peritoneal sepsis, enhances survival, induces protection against bacterial colonization of peritoneal fluid and increasing in leukocite migration.

Key words: Glucan. Sepsis. Survival. Leukocite migration. Bacterial colony.

\section{Introdução}

A terapêutica da sepse continua a representar um desafio para a medicina. Apesar dos avanços no seu tratamento com a evolução dos agentes antimicrobianos e medidas de suporte vital, tem sido demonstrado que todos esses esquemas não são suficientes para diminuir a morbidez e mortalidade, que se mantêm crescentes a cada dia. É de grande importância a manutenção da imunocompetência dos pacientes, uma vez que é fundamental a resposta imune frente às infecções. A estimulação desta resposta tem sido considerada de grande relevância no combate aos microrganismos estranhos ${ }^{1,2}$.

Dentre as substâncias imunoestimulantes destaca-se a glucana, um polissacarídeo composto de unidades de glicopiranoses unidas por ligações glicosídicas ?? 1-3 de alto peso molecular, extraído da parede celular interna do fungo Saccharomyces cerevisiae $^{3,4,5}$. Tem sido descrito que a glucana apresenta uma ampla e potente atividade sobre o sistema reticuloendotelial (SRE) ${ }^{1,6,7}$. Sua administração está associada a um estado de hiperfagocitose e hipertrofia de órgãos reticuloendoteliais, devido ao aumento no tamanho e número dos macrófagos $8,9,10,11$.

Alguns estudos vêm enfatizando a participação da glucana semi-solúvel aminada (GSA), administrada por via intraperitoneal (i.p.), na capacidade de eliminação de bactérias da cavidade peritoneal em camundongos desafiados com Escherichia coli ${ }^{12,13}$. O estudo aqui descrito procurou investigar a ação da glucana em modelo experimental de sepse analisando a sobrevida, migração leucocitária e contagem de unidades formadoras de colônias bacterianas. 


\section{Métodos}

Foram utilizados, neste estudo, camundongos machos e fêmeas, de linhagem Swiss de 6 a 8 semanas de idade. Os camundongos foram mantidos no biotério do Centro de Ciências da Saúde-UFRN com água e alimentação ad libitum.

Glucana ?? 1-3 insoluvel (particulada) foi preparada a partir do fermento comum Saccharomyces cerevisae, pela técnica de Hassid modificada ${ }^{6}$.

\section{Protocolo com glucana em camundongos Swiss com sepse experimental}

Os animais foram divididos em dois grupos: o primeiro recebeu injeção i.p. de 5 ou $10 \mathrm{mg}$ de glucana/ $1 \mathrm{~mL}$ de solução salina estéril no dia 0 , com mais duas aplicações subseqüentes nos dias 4 e 8 . Os animais controles foram injetados apenas com $1 \mathrm{~mL}$ de solução salina estéril seguindo os mesmos intervalos. No dia 12 foi realizada a indução de sepse experimental e feito o seguimento do tempo de sobrevida. Em experimentos posteriores após seis horas da indução de sepse foram avaliadas a migração leucocitária e as unidades formadoras de colônias bacterianas (UFC).

\section{Protocolo experimental de sepse I}

Os grupos foram submetidos ao modelo de sepse denominado transfixação do coto-cecal $^{14}$. Após a anestesia i.p. com pentobarbital $20 \mathrm{mg} / \mathrm{kg}$ e depilação da parede abdominal, a assepsia do campo operatório foi feita com povidona. A cavidade peritoneal foi exposta, por meio de uma incisão mediana de $2 \mathrm{~cm}$ e o ceco exteriorizado com auxílio de uma pinça cirúrgica. Com um fio de algodão 2-0 agulhado foi feita a ligadura do ceco a um centímetro da válvula ileocecal. Após a ligadura, o coto isolado do ceco foi transfixado com a agulha do próprio fio a partir do ponto de ligadura até a porção mais distal do ceco. O fio foi seccionado a um centímetro do ponto de saída, funcionando desse modo como dreno do conteúdo cecal para acavidade peritoneal ${ }^{14}$.

\section{Sobrevida}

Após a indução de sepse foi avaliado o tempo de sobrevida dos animais. Os camundongos foram tratados com 5 ou 10mg de glucana i.p.em três intervalos de 72 horas, 
e o grupo controle com solução salina. A percentagem de sobrevida de cada grupo (n=05) foi determinada pela sobrevivência do animal em relação às horas e dias. Os dados foram representativos de três experimentos independentes: sobrevida, contagem de colônias bacteriana e contagem de leucócitos.

\section{Migração de leucócitos no lavado peritoneal e contagem no sangue periférico}

Os animais do grupo experimental foram tratados com dose adicional de $5 \mathrm{mg}$ de glucana/animal e o grupo controle recebeu solução salina estéril. Após seis horas da indução da peritonite todos os animais inalaram éter, e foram sacrificados pelo descolamento cervical. Foi realizada a assepsia com álcool $70 \%$ no abdome dos animais, e injetados $3 \mathrm{~mL}$ de PBS estéril contendo EDTA (1mM ) na cavidade peritoneal. O plexo retro-orbital foi puncionado para colheita de sangue. $\mathrm{O}$ aspirado peritoneal e o sangue periférico foram coletados e acondicionados em ependorfes, sendo a leitura realizada pelo Contador Hematológico Automatizado (micro-60 ABX).

\section{Quantificação das unidades formadoras de colônias bacterianas}

Após $6 \mathrm{~h}$ da indução da sepse, os animais foram submetidos ao mesmo protocolo da técnica citada no item anterior, sendo que os animais receberam tratamento com 5 ou 10mg de glucana por via i.p. O aspirado peritoneal foi coletado e feitas diluições do exsudato na concentração de 1:10 (1 parte de exsudato e 9 partes de PBS estéril). Em seguida, alíquotas foram semeados em placas de Petri em meio de cultura Mueler Hinton; a semeadura foi realizada com alça bacteriológica, mantendo-se as placas em estufa a 37C?, por 12 h, para realização da contagem de colônias bacterianas viáveis.

\section{Estatística}

Foi utilizada a análise de variância ANOVA, seguida pelo teste de Tukey, considerando-se significante quando $\mathrm{p}<0,05$.

\section{Resultados}

A sobrevida dos animais foi avaliada através da contagem do número de horas e dias, a partir da indução de sepse. Os dados mostraram que, com 120 horas de observação, $93 \%$ dos que usaram $5 \mathrm{mg}$ de glucana e $87 \%$ dos tratados com 10mg da droga estavam 
vivos, enquanto apenas $20 \%$ do grupo controle sobreviveu até este período, caracterizando uma diferença estatisticamente significante ( $\mathrm{p}<0.01)$ (Figura 1). No 16? dia de observação, $87 \%$ (5mg) e $86 \%$ (10mg) dos animais tratados com glucana estavam vivos, enquanto apenas $20 \%$ do grupo controle sobreviveu até esse período. A diferença mostrou-se significante, com $\mathrm{p}<0.01$ (Figura 1).

A

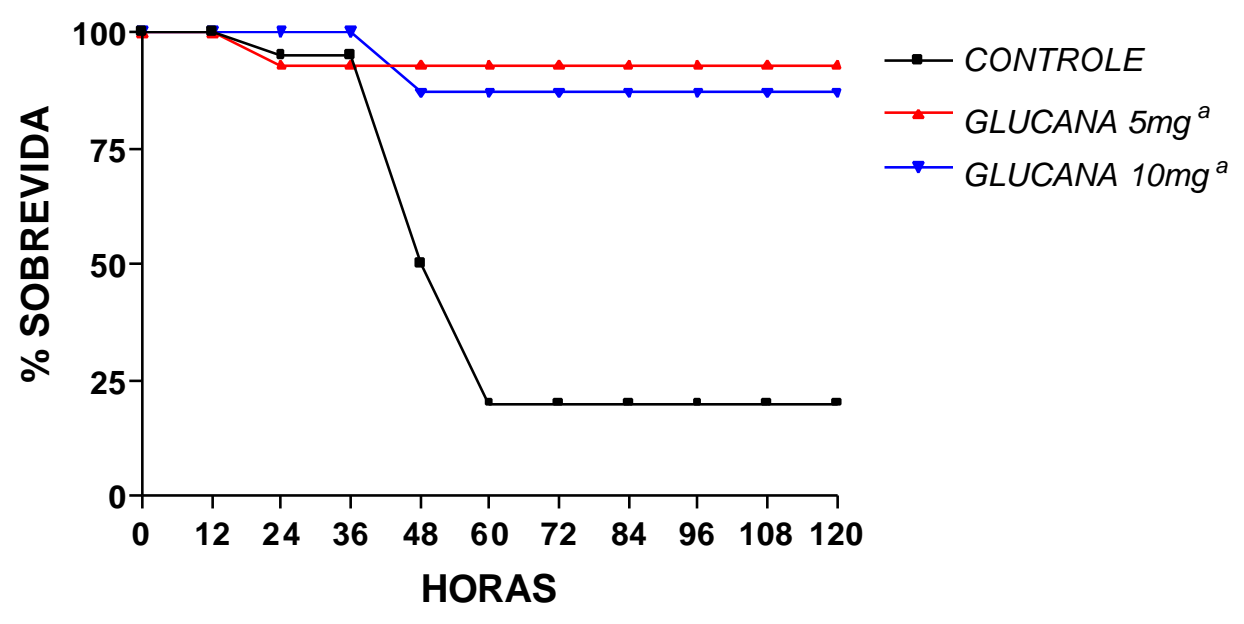

B

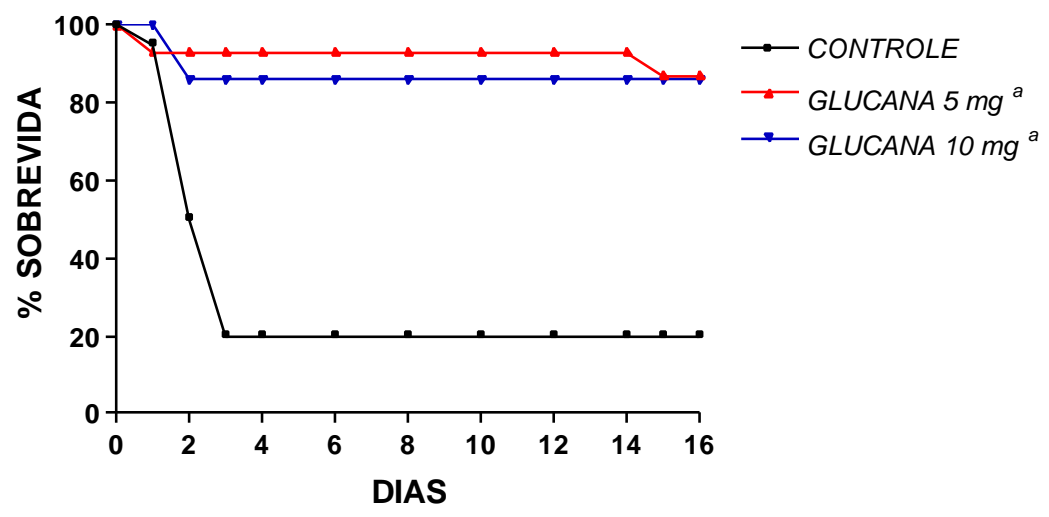

FIGURA 1 - Sobrevida (em horas e dias) de camundongos Swiss submetidos à indução de sepse, após tratamento com 5 ou $10 \mathrm{mg}$ de glucana. Painel A e B ${ }^{\mathrm{a}} \mathrm{p}<0.01$ comparado em relação ao controle (ANOVA, seguido pelo teste de Tukey).

Migração de leucócitos no lavado peritoneal e contagem no sangue periférico após tratamento com glucana e desafio com sepse 
A finalidade foi avaliar a capacidade da glucana em recrutar a população de células responsáveis pela resposta inflamatória. Os resultados mostraram um aumento na migração de leucócitos no exsudato peritoneal no grupo tratado com glucana, sendo estatisticamente significante quando comparada com o grupo controle (Figura 2). Pode-se observar que não houve diferença significante entre o número de leucócitos do sangue periférico dos animais tratados com glucana e o grupo controle (Figura 2).

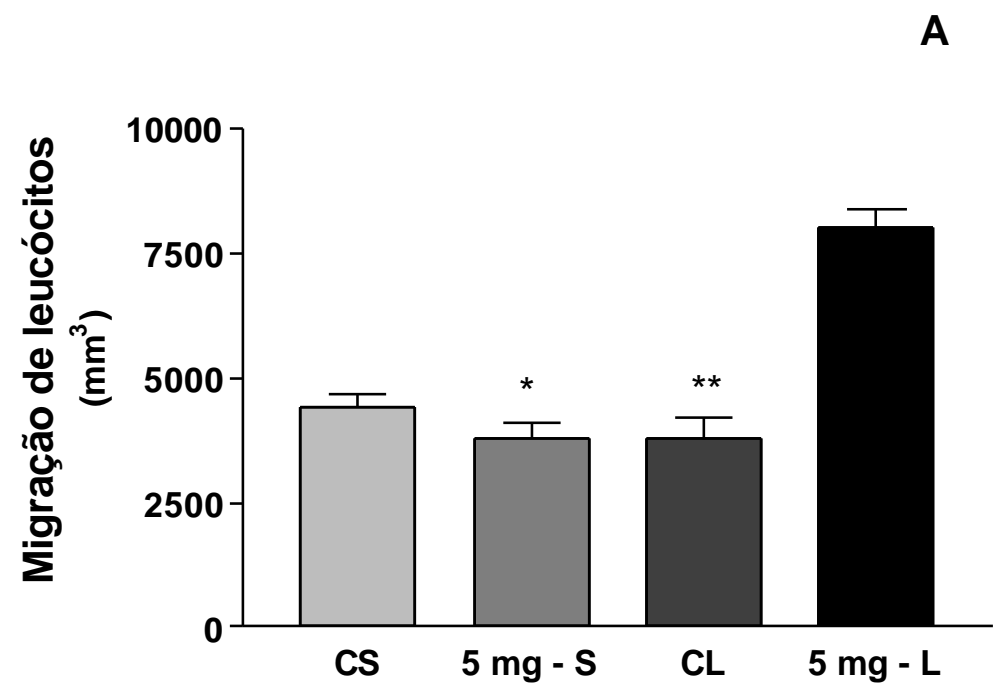

FIGURA 2 - Migração de leucócitos no líquido peritoneal e contagem no sangue periférico, após 6 horas de indução de sepse em camundongos tratados com glucana. ( Legenda: $\mathrm{CS}=$ controle sangue; $5 \mathrm{mg}-\mathrm{S}=$ glucana $5 \mathrm{mg}$ sangue; $\mathrm{CL}=$ controle líquido peritoneal; $5 \mathrm{mg}-\mathrm{L}=$ glucana $5 \mathrm{mg}$ líquido peritoneal).

As barras da Figura 2 representam as médias?dp obtidas da contagem de leucócitos de cada grupo $(\mathrm{n}=5)$, e os resultados são representativos de dois experimentos independentes. Comparado-se a contagem de leucócitos no lavado peritoneal do grupo tratado com glucana $(5 \mathrm{mg}-\mathrm{L})$ em relação ao número de leucócitos no sangue periférico do mesmo tratamento $(5 \mathrm{mg}-\mathrm{S})$ e com o lavado peritoneal do grupo controle (CL), a diferença foi significante $(\mathrm{p}<0,001)$.

\section{Contagem das UFC no lavado peritoneal após indução de sepse}

A coleta do exsudato peritoneal para a quantificação do número de bactérias presentes no lavado peritoneal foi realizada após 6 horas da indução de sepse. Os camundongos tratados com glucana mostraram uma quantidade inferior na contagem de colônias bacterianas no lavado peritoneal quando comparada com o grupo controle. A 
média da contagem das UFC no grupo controle foi de 7,6? 1,8 colônias/mL de exudato, enquanto nos grupos de animais tratados com glucana, 5 ou $10 \mathrm{mg}$ foram de 3,0 ?1,3 colônias/mL, e 2,7?1,3 colônias/mL, respectivamente, sendo estas diferenças estatisticamente significantes (Figura 3). Pode-se inferir portanto, que a glucana proporcionou um intenso recrutamento de macrófagos e neutrófilos mostrado durante o processo infeccioso e que essas células conferiram uma capacidade maior para combater bactérias patogênicas na cavidade peritoneal.

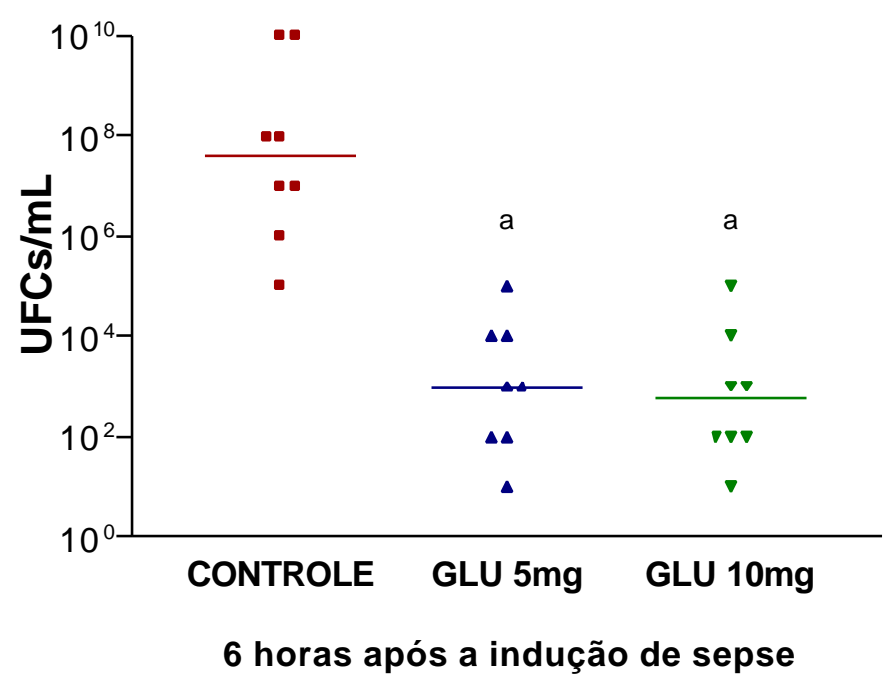

FIGURA 3 - Quantificação das unidades formadoras de colônias (UFC) no exsudato peritoneal de camundongos Swiss tratados com glucana, e submetidos a modelo de sepse experimental. A média? DP foi obtida da contagem de cada grupo $(n=4)$ e representativo de dois experimentos independentes. ${ }^{a} \mathrm{p}<0.01$ quando comparado com o grupo controle (ANOVA, seguido pelo teste de Tukey).

\section{Discussão}

Na tentativa de entender a ação da glucana particulada como uma substância imunoprotetora durante a infecção por sepse, camundongos foram submetidos ao modelo de transfixação do coto-cecal. A análise foi realizada pela observação do tempo de sobrevida, migração leucocitária no exsudato peritoneal e quantificação de unidades formadoras de colônias bacterianas no exudato peritoneal. Em relação à sobrevida, esses achados demonstraram que os camundongos Swiss tratados com glucana apresentaram uma maior sobrevida. Estes resultados se assemelham com trabalhos anteriores em que demonstraram a participação da glucana semi-solúvel no aumento do tempo de sobrevida 
em camundongos desafiados i.v. com 2.5 x10 Stafilococos aureus quando comparados com animais controles ${ }^{15}$. Outros autores têm mostrado em modelo experimental de sepse, que a glucana age estimulando diretamente os macrófagos, aumentando sua capacidade fagocítica, contribuindo para a redução da bacteremia por Gram-negativas, limitando os danos aos órgãos reticuloendoteliais e conseqüentemente proporcionando uma maior sobrevida $^{12,16,17,18}$.

Os resultados referentes à migração de leucócito no exsudato peritoneal mostraram que os animais tratados com glucana apresentaram um aumento no número de leucócitos como neutrófilos e monócitos, e não foi evidenciado um aumento do número de leucócitos no sangue periférico, provavelmente porque estas células tenham sido recrutadas para a cavidade abdominal. Estes resultados estão em concordância com a literatura, que mostra que glucana proporciona um aumento da migração leucocitária no esxudato peritoneal no local do desafio, resultando na diminuição da contagem dos leucócitos no sangue periférico devido a esse intenso recrutamento celular ${ }^{19,20}$.

O preciso mecanismo de ação da glucana na indução da neutrofilia não está completamente elucidado. Entretanto, vários experimentos em camundongos sugerem que a administração da glucana induz a síntese de fatores estimulantes de colônia para monócitosgranulócitos (GM-CSF), que implica no aumento da produção, recrutamento, e/ou liberação de neutrófilos da medula óssea ${ }^{21,22,23}$.

Um estudo realizado por Engstad et al ${ }^{5}$ mostrou que glucana ?? 1-3 solúvel tem sido importante pelo fato de ativar leucócitos de camundongos, protegendo-os contra infecção e choque por sepse. Wakshull et al $^{12}$ mostraram em seu trabalho in vitro que neutrófilos-PMN incubados com glucana semi-solúvel, e particulada em dose dependente, tiveram aumento da resposta da explosão respiratória e desenvolveram atividade microbicida devido à glucana proporcionar a ativação do fator NF-?B. Vários trabalhos vêm enfatizando a participação da glucana semi-solúvel no aumento da capacidade de eliminação do número de bactérias da cavidade peritoneal em murino desafiado com E. coli 20,24,25. Os dados apresentados neste trabalho mostram que os animais que receberam tratamento com glucana particulada apresentaram uma diminuição na contagem de UFC bacterianas no lavado peritoneal, entretanto, não foi observada diferença quando foi usada a dose de $5 \mathrm{mg}$, em relação à infusão de $10 \mathrm{mg}$ de glucana i.p. Este achado pode ser atribuído à 
ativação sistêmica do SRE, bem como, à ativação de macrófagos e diferentes tipos de células em animais tratados com glucana, e submetidos a diferentes modelos de sepse experimental $^{12,17,26 .}$

\section{Conclusão}

A glucana insolúvel, quando usada em camundongos por via intraperitoneal, em modelo de sepse abdominal, contribuiu para melhorar a sobrevida, induziu proteção contra a formação de colônias bacterianas no líquido peritoneal e aumentou a migração leucocitária.

\section{Referências}

1-Williams DL. Effect of glucan on neutrophil dynamics and immune function in Escherichia coli peritonitis. J Surg Res 1988; 44(1):54-61.

2-Tsukahara Yl. Expression of inducible nitric oxide synthase in circulating neutrophils of the systemic inflammatory response syndrome and septic patients. World J Surg $1998 ; 22(8) 771-7$.

3-Mullen PG. Receptor binding and internalization of a water - soluble (1? 3)-ß-D-glucan biologic response modifier in two monocyte/macrophage cell lines. J Immunol 1996;156 (9):3418-25.

4-Tsiapali El. Glucans exhibit weak antioxidant activity, but stimulate macrophage free radical activity. Free Rad Biol Med 2001;30(4):393-402.

5-Engstad CS. The effect of soluble ?? 1,3-glucan and lipopolysaccharide on cytokine production and coagulation activation in whole blood. Immun Pharmacol 2002;2:25-32.

6-Hasssi D. The molecular constitution of an insoluble polysaccharide from yeast, Saccharomyces cerevisiae. J Am Chem Soc 1941;63:295-8.

7-Ross GD. Therapeutic intervention with complement and ?-glucan in cancer. Immunopharmacol 1999; 42:61-74. 
8-Di Luzio N.R. . Glucan - induced enhancement in host resistance to experimental tumors. In: Chirigos MA. (Ed.). In: Control of neoplasia by modulation of the immune system. New York: Raven Press, 1977. p. 475-99.

9-Wolk M, Danon D. Promotion of wound healing by yeast glucan evaluated on single animals. Med Biol 1995; 63: 73-80.

10-Lehnborg G, Hedström KG, Nord CE. The effect of glucan - A host resistance activator and ampilicillin on experimental intra-abdominal sepsis. J Reticul Soc 1982; 32(5): 347-53.

11-Sakurai TL. Different role of serum components and cytokines on alveolar macrophage activation by soluble fungal (1? 3)-? -D-glucan. Eur J Pharmacol 1997;334:255-63.

12-Wakshull E. PGG-Glucan, a soluble ?-(1-3)-glucan, enhances the oxidative burst response, microbicidal activity, and activates an NF-KB-like factor in human PMN: evidence for a glycosphingolipid ?-(1-3)-glucan receptor. Immunopharmacol 1999; 41:89107.

13-Martineau L. Peritoneal cytokine concentrations and survival outcome in na experimental bacterial infusion model of peritonitis. Crit Care Med 2000;28(3)788-94.

14-Aguiar JLA, Moreira IEG, Chaves MM, Lopes SL, Santana V. Peritonite experimental: modificação técnica do modelo de ligadura de ceco em ratos. An Fac Med Univ Fed Pernamb 1996; 41(1): 59-62.

15-Di Luzio NR, Williams D L. Protective effect of glucan against systemic Staphylococcus aureus septícemia in normal and leukemic nice. Infect Immun 1978;20(3): 804-10.

16-Williams DL, Browder IW, Di Luzio NR. Immunotherapeutic modification of Escherichia coli-induced experimental peritonitis and bacteremia by glucan. Surgery 1981; 93(3):448-54.

17-Almdahl SML. The effect of splenectorny on Escherichia coli sepses and its treatment with semisoluble aminated glucan. Scand J Gastroenterol 1987; 22: 261-7. 
18-Konopski Z, Seljelid R, Eskeland T. IFN-? inhibits internalization of soluble aminated ?-1, 3-D-glucan bymacrophages and thereby down-regulates the glucan induced release of TNF-? and IL-1?. Scand J Immunol 1994;40:57-63.

19-Araki A. Enhancement of polymorphonuclear Leukocyte-mediated tumor cytotoxicity by serum factor(s). Jpn J Cancer Res 1990;18:69-78.

20-Abel CZOP JX. Stimulation of human monocyte B - glucan receptors by glucan particles induces production of TNF-? and IL- 1? . Int J Immunoph 1992; 14(8):1363-73.

21-El Saghir N. Pressure ulcer accelerated healing with local injections of granulocyte macrophage-colony stimulating factor. Immun Pharmacol 1996;6:445-65.

22-Wang H. Effects of lectins with different carbohydrate-binding specificities on hepatoma, choriocarcinoma, melanoma and osteosarcoma cell lines. Int J Biochem Cell Biol 2000; 32(3):365-72.

23-Couso N. Location of superoxide production sites in turbot neutrophils and gilthead seabream acidophilic granulocytes during phagocytosis of glucan particles. Develop Comp Immunol 2001;25:607-18.

24-Rasmussen LT, Fandrem J, Seljelid R. Dynamics of blood components and peritoneal fluid during treatment of murine E. coli sepsis with ?-1, 3-D-polyglucose derivatives. Scand J Immunol 1990;32(4):333-40.

25-Hoffman O A, Olson EJ, Limper AH. Fungal ?-glucans modulate macrophage release of tumor necrosis factor-? in response to bacterial lipopolysaccharide. Immunol Letters 1993;37:19-25. 
26-Williams JD. Activation of human polymorphonuclear leucocytes by particulate zymosan is related to both its major carbohydrate components: glucan and mannan. Immunology 1986;58(1):117-24.

\author{
Correspondência: \\ Janaina Cristiana de Oliveira Crispim Freitas \\ Av. do Café, 1139/D-405 \\ 14050-230 Ribeirão Preto - SP \\ janacrispim@hotmail.com \\ Data do recebimento: 23/02/2004 \\ Data da revisão: 19/03/2004 \\ Data da aprovação: 06/04/2004 \\ Conflito de interesse: nenhum \\ Fonte de financiamento: nenhuma
}

\title{
Como citar este artigo:
}

Crispim JCO, Medeiros AC, Sales VSF. Proteção pela glucana em modelo experimental de sepse. Acta Cir Bras [serial online] 2004 Maio-Jun;19(3). Disponível em URL: http://www.scielo.br/acb. [also in CD-ROM]. 